\title{
Predicting pulmonary function after lung resection: Did you account for induction chemoradiation?
}

\author{
Varun Puri, MD, MSCI \\ From the Department of Cardiothoracic Surgery, Washington University School of Medicine in St Louis, St Louis, \\ Mo. \\ V.P. was supported by K07CA178120. \\ Disclosures: Author has nothing to disclose with regard to commercial support. \\ Received for publication Feb 8, 2018; revisions received Feb 8, 2018; accepted for publication Feb 11, 2018; \\ available ahead of print March 6, 2018. \\ Address for reprints: Varun Puri, MD, MSCI, Department of Cardiothoracic Surgery, Washington University \\ School of Medicine in St Louis, 660 S Euclid Ave, Campus Box 8234, St Louis, MO 63110 (E-mail: \\ varunpuri@wustl.edu). \\ J Thorac Cardiovasc Surg 2018;155:2138-9 \\ $0022-5223 / \$ 36.00$ \\ Copyright (C) 2018 by The American Association for Thoracic Surgery \\ https://doi.org/10.1016/j.jtcvs.2018.02.020
}

In their study in this issue of the Journal, Nomori and colleagues ${ }^{1}$ have elegantly demonstrated that induction chemoradiotherapy is associated with reduced pulmonary function after lobectomy as a result of a decrease in ipsilateral preserved lobe function. They hypothesize that this is likely related to the chronic effect of the induction chemoradiotherapy. With a combination of physiologic and anatomic testing, they also found that contralateral lung function is increased after lung resection, somewhat mitigating the effects of the induction therapy. These findings are clinically useful and merit further discussion.

First, though it has been well recognized that thoracic radiation therapy compromises subjective and objective assessments of pulmonary function, it is not commonly appreciated in the surgical community that the response can be biphasic. ${ }^{2}$ Radiation pneumonitis, which can occur in the acute or subacute setting, manifests itself as cough, dyspnea, and patchy infiltrates and occurs in fewer than $15 \%$ of patients undergoing thoracic radiation therapy. Risk factors for radiation pneumonitis include the volume of lung included in the field, the radiation dose, and previous irradiation. Radiation pneumonitis is usually managed with oral steroid administration, although, because of the possible underlying immune mechanisms, classic immunosuppressive agents have also been used. Late radiation injury is associated with pulmonary fibrosis and leads to progressive dyspnea accompanied by decreased lung compliance that lowers the forced vital capacity ${ }^{2}$ and the diffusing capacity for carbon monoxide. Radiation fibrosis is generally managed with supportive care, and no specific agents have been shown to change the course of the disease.

Second, the phenomenon of compensatory lung growth after lung resection remains inadequately understood. Animal studies clearly demonstrate contralateral lung growth

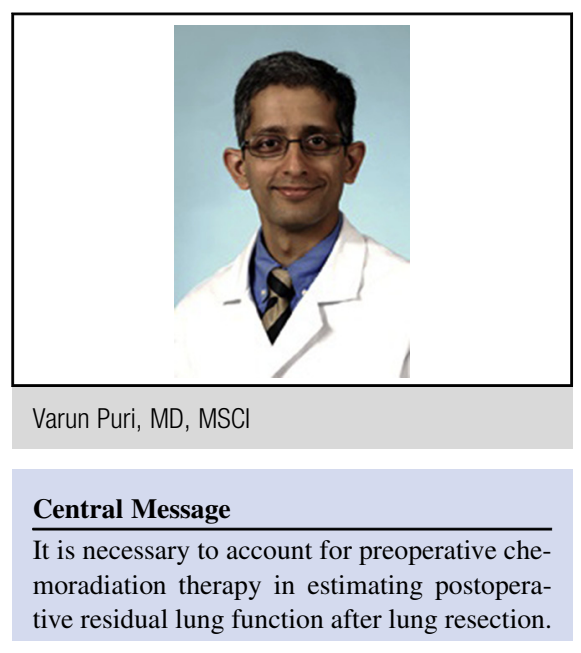

See Article page 2129. after pneumonectomy, with an increase in alveoli as well as in lung volume. ${ }^{3}$ This growth is likely reflected clinically in a less than expected decline in lung function after anatomic lung resection, a commonly recognized occurrence. Greater understanding of this phenomenon is critically important, because standard methods of predicting postoperative lung function do not account for compensatory lung growth. With the increasing role of nonoperative therapy in high-risk patients with lung cancer, it is vital to understand clearly the objective posttreatment parameters of lung function.

Finally, the study by Nomori and colleagues ${ }^{1}$ reiterates the significance of repeating pulmonary function testing after induction therapy and before lung resection for accurate risk assessment. Unfortunately, despite widely available detailed guidelines on the oncologic aspects of care for patients with locally advanced lung cancer, physiologic assessment such as lung function is not commonly systematized. In addition, payers may raise objections to repeating preoperative pulmonary function tests. In such a situation, a low-cost, reliable alternative may be to perform handheld spirometry as a surrogate for formal laboratory pulmonary function testing. ${ }^{4}$

\section{References}

1. Nomori H, Shiraishi A, Cong Y, Shoji K, Misawa M, Sugimura H, et al. Impact of induction chemoradiotherapy on pulmonary function after lobectomy for lung cancer. J Thorac Cardiovasc Surg. 2018;155:2129-37.e1.

2. Abratt RP, Morgan GW. Lung toxicity following chest irradiation in patients with lung cancer. Lung Cancer. 2002;35:103-9. 
3. Takahashi Y, Izumi Y, Kohno M, Kawamura M, Ikeda E, Nomori H. Airway administration of dexamethasone, $3^{\prime}-5^{\prime}$-cyclic adenosine monophosphate, and isobutylmethylxanthine facilitates compensatory lung growth in adult mice. Am J Physiol Lung Cell Mol Physiol. 2011;300:L453-61.
4. Hudson JL, Bell JM, Crabtree TD, Kreisel D, Patterson GA, Meyers BF, et al. Office-based spirometry: a new model of care in preoperative assessment for low-risk lung resections. Ann Thorac Surg. 2018;105: 279-86. 